\title{
Alfred de Musset, La Nuit vénitienne, Le Chandelier, Un Caprice, Il faut qu'une porte soit ouverte ou fermée
}

\section{Valentina Ponzetto}

\section{(2) OpenEdition}

1 Journals

\section{Edizione digitale}

URL: http://journals.openedition.org/studifrancesi/5691

DOI: 10.4000/studifrancesi.5691

ISSN: 2421-5856

\section{Editore}

Rosenberg \& Sellier

\section{Edizione cartacea}

Data di pubblicazione: 1 septembre 2011

Paginazione: 440

ISSN: 0039-2944

\section{Notizia bibliografica digitale}

Valentina Ponzetto, «Alfred de Musset, La Nuit vénitienne, Le Chandelier, Un Caprice, II faut qu'une porte soit ouverte ou fermée», Studi Francesi [Online], 164 (LV | II) | 2011, online dal 30 novembre 2015, consultato il 08 janvier 2021. URL: http://journals.openedition.org/studifrancesi/5691 ; DOI: https:// doi.org/10.4000/studifrancesi.5691

Questo documento è stato generato automaticamente il 8 janvier 2021.

\section{(c) $(1) \ominus$}

Studi Francesi è distribuita con Licenza Creative Commons Attribuzione - Non commerciale - Non opere derivate 4.0 Internazionale. 


\title{
Alfred de Musset, La Nuit vénitienne, Le Chandelier, Un Caprice, Il faut qu'une porte soit ouverte ou fermée
}

\author{
Valentina Ponzetto
}

\section{NOTIZIA}

ALFRED DE MUSSET, La Nuit vénitienne, Le Chandelier, Un Caprice, Il faut qu'une porte soit ouverte ou fermée, éd. Frank LESTRINGANT, Paris, Gallimard, «Folio théâtre», 2010, 402 pp.

1 Con una scelta curiosa, il presente volume riunisce, quasi in una sorta di antologia, quattro pièces di Musset assai lontane tra loro per ispirazione e data di composizione, dalla Nuit vénitienne, esordio sulle scene dell'autore nel 1830, a Il faut qu'une porte soit ouverte ou fermée, opera della maturità (1845) e ultima delle Comédies et proverbes ancor oggi regolarmente rappresentate. Esse forniscono un esempio di tre dei quattro periodi o tipi di ispirazione successivi individuati da Frank Lestringant nel teatro mussettiano: gli esordi sotto il segno del romanticismo, di Shakespeare e di Schiller, dai toni cupi, ma al tempo stesso critici e ironici, soprattutto nei confronti dei connazionali e contemporanei quali Hugo e Dumas (La Nuit vénitienne); il ritorno ad una vena di tradizione francese, ispirata a Molière ma anche a Beaumarchais e Regnard, per dipingere la provincia francese del regno di Louis-Philippe (Le Chandelier); e infine l'epoca del proverbe de salon, caratterizzata dalla rivisitazione di Carmontelle e Marivaux e dalla nostalgia per un Settecento idealizzato (Un Caprice, Il faut qu'une porte soit ouverte ou fermée), a cui seguirà una quarta e ultima epoca, qui non rappresentata, di commedie delicate, melanconiche, desuete e fuori del tempo.

2 Il ritratto di Musset che il critico traccia nell'introduzione è del resto quello di un drammaturgo esperto ed efficace, ottimo conoscitore della tradizione teatrale, pronto a mescolarne e sovvertirne i modelli con cognizione di causa, perfettamente conscio del proprio mestiere ed anzi dotato di quella «merveilleuse divination des planches» che 
Théophile Gautier aveva per primo saputo riconoscere al momento della rivelazione di Un Caprice sulle scene nel 1847. «Divinazione» che in realtà, sottolinea l'autore, non ha nulla di magico o di miracoloso, ma è frutto di una lunga e costante frequentazione del mondo teatrale e della letteratura drammatica, nonché il segno più evidente che Musset, pur adottando la sdegnosa formula dello Spectacle dans un fauteuil, ha sempre scritto per la scena, creando personaggi quanto mai vivi e concreti, pronti per trovare corpo e voce negli attori.

3 Un'analisi più puntuale, fondata su esempi testuali, è poi dedicata ad alcuni punti forti di questa drammaturgia: la costruzione dello spazio, l'inserzione costante della musica nella tessitura del testo, i temi fondamentali del caso, del capriccio e del jeu, inteso sia come finzione scenica, sia come pulsione ludica, sia come vero e proprio gioco d'azzardo, e infine l'arte della schermaglia amorosa che regola i rapporti fra i personaggi, rituale antiquato eppure intramontabile e sempre attuale.

4 Il testo delle pièces, basato sull'edizione preoriginale apparsa sulla «Revue des deux mondes», è seguito da una cronologia, una bibliografia selettiva, un riassunto di ogni opera e delle documentatissime Notices che ricostruiscono per ciascuna le fonti di ispirazione, la genesi e un panorama della fortuna teatrale dalla creazione ai giorni nostri. 